\title{
Forecasting office rentals in Gaborone in the short and long term
}

\author{
J. Kampamba ${ }^{1}$ \& C. E. Cloete ${ }^{2}$ \\ ${ }^{1}$ Department of Civil Engineering, University of Botswana, Botswana \\ ${ }^{2}$ Department of Construction Economics, \\ University of Pretoria, South Africa
}

\begin{abstract}
The purpose of the study was to forecast office rentals in the city of Gaborone, Botswana. A model was developed to assist in the evaluation of proposed investments and developments. The study was both qualitative and quantitative in nature. The sample was determined at $95 \%$ confidence level with a $5 \%$ margin of error and $40 \%$ chance that the picked respondents were dealing in offices. The data obtained from the 30 respondents was analysed using regression analysis models, Microsoft Excel and SPSS 16.0 package to determine the relationship between prosperity (GDP growth) and levels of rentals. The moving average method (MAM) of office rentals between 2008 and 2014 was used to derive the direction of rental values in the four office nodes in Gaborone. The findings indicate that rentals are expected to increase at various rates in the four areas under investigation. This study is the first of its kind in Botswana and should be useful to real estate professionals, financial institutions, tenants and academics.

Keywords: forecasting, moving average method, real estate, office rentals, Gaborone, Botswana.
\end{abstract}

\section{Introduction}

Botswana is a middle income country located in Southern Africa with an area of about 581,730 square kilometres and a population of about 2 million. The GDP per capita income was $\$ 16,400$ with a growth rate of $3.9 \%$ (2013), the unemployment rate was $17.8 \%$ (2013) and the inflation rate was $7.5 \%$ in 2012 and $6.1 \%$ in 2013 . Economic activity is centred on diamond mining, which contributes about $30 \%$ towards the GDP. 
Gaborone is the capital city of Botswana. Boosted by robust economic growth, the commercial and industrial real estate sectors in Botswana have performed well recently [1]. High prices in the purchase and rental market in Gaborone are attributed to a strong demand and limited supply [2].

The purpose of this study was to establish the future performance of office property in Gaborone by undertaking a market feasibility study and forecast the trend of rentals in the short and long term. Office property rental data were obtained from the data bases of 30 brokers active in the area of investigation. Data was obtained for the period 2008 to 2014, in four different office nodes in Gaborone. From this data, conclusions were drawn about the expected future performance of office property. The rental values of office properties for the period under consideration were calculated using the moving average method (MAM) in order to establish the trend in office rentals. These values were plotted using regression analysis model equations.

\section{Research objectives}

The purpose of this study was:

- $\quad$ to forecast and project rentals both in the short and long run;

- $\quad$ to plot the forecasted rentals using the moving average method (MAM);

- to create model equations using regression analysis that can be used to forecast office rentals in Gaborone.

\section{Literature review}

Literature was reviewed along two themes: factors considered in determination of rental levels, and influence of occupiers' characteristics in office accommodation decisions.

\subsection{Determination of rental levels and earlier studies}

Cloete [3] identified twelve major factors to be considered when determining the rental of an office building. These in order of importance are location, neighbourhood, transportation, prestige, appearance, entrance hall, lifts, corridors, office interiors, tenant services, management and tenant mix. Serero and Kampamba [4] in their study of the housing market cycles in Botswana found that Botswana is one of the countries that has never experienced a severe recession like, for example, Germany. Kampamba and Cloete [5] in their study on the office market in Botswana investigated the problems and prospects within the office market environment and established that office rentals were increasing year by year during the period preceding the study.

A limited number of studies on forecasting of demand for office space and rentals have been carried out in the past (see e.g. [6]). According to Nwuba [7] the need to analyse the movement of rents is premised on the fact that it would aid entrepreneurs in their planning and cash flow projections; assist developers in investment decision making; useful to real estate professionals in appraisals and 
evaluation of proposed development projects as well as provide information for researchers. On the other hand, Oni [8] conducted a study in Nigeria to determine demand for commercial properties along arterial roads and developed models for predicting demand and commercial property values in Ikeja. In a study by Matysiak and Tsolacos [9] it was stated that in the office sector, economic variables that affect the performance are the gross domestic product, output and employment in financial and business services, unemployment, interest rates and operating expenses. One of the earliest attempts to explain the determinants of office rents was carried out by Guardiner and Henneberry, cited by Kiehela and Falkenbach [10]. In a study by McGough and Tsolacos [11] it was mentioned that the existing empirical work on the prediction of rental values is based mainly on dynamic specifications. A model of regional office rents was estimated over a period 1979 to 1984 and was used to forecast the rental values for 1985 [11].

\subsection{Influence of occupiers' characteristics in office accommodation decisions}

Basically, all firms would choose to settle in a centre that offers comparative advantages, such as proximity to labour markets and suppliers, accessibility to major transportation systems and convenience of face to face contacts. This is typical of any office accommodation that is offered in the market. The agglomeration of firms gives rise to a nucleus city with high concentration of employments, which evolves over time in a CBD (Central Business District) $[12,13]$. The "history" of the CBD location as a result of the sunken costs and infrastructure built-in creates the first mover disadvantage and increases firms' inertia to relocate from their CBD premises [14]. However, when the CBD grows and reaches a critical size, the agglomeration benefits of the CBD diminish as a result of the growing costs of traffic congestion, parking problems/shortage and the increased office density. The firms' inertia of relocation is weakened and it is more ready to trade off the agglomeration economies for new office locations in the fringe areas, which offer lower density office space with newer facilities at lower costs. As a result, subcentres are formed to accommodate the outward movement of firms from the existing CBD $[15,16]$. The decentralisation process can be accelerated with the advancement of the information and communications technology that breaks down the geographical barrier and reduces the significance of face-to-face contacts in the CBD [17].

The issues of location determinants and inverse bid rent gradient have been widely researched in urban economics literature (Clapp [18]; Archer [19]; Dunning and Norman [20]; Rauch [14]; Bollinger et al. [21]). The rent function is invariably represented by specifications that consist mainly of location characteristics of offices. On the demand side, the assumptions that firms are rational and homogenous and that it has perfect information in its location choice decision were also increasingly questioned by researchers in behavioural studies, Wyatt [22]; Leishman and Watkins [23]; Leishman et al. [24].

The classical urban economics literature on location choice of office space is developed on the assumption that there exists only one unitary urban city centre where firms could enjoy agglomeration economies by locating in the centre. The 
classical Alonso's [25] bid rent function declines with the distance away from the CBD, and firms will have to trade off accessibility for larger office space in the fringe location. Clapp [18] tested the rent accessibility trade off using 105 office buildings' data in Los Angeles, and found significant evidence to support the negative rental function with respect to the distance from the CBD and commuting time. His results also supported the importance of face-to-face interaction in the CBD. Using a more recent set of office rental data in Greater Los Angeles from the same source (Coldwell Banker database), Sivitanidou [26] again found that the accessibility factors (distance from the CBD, distance from the airport and the number of freeways) are significantly reflected in variations of the office rental function.

However, she also found that the standard bid rent function is incomplete in explaining office rent relationships unless other variables like worker amenities, zoning and local institutional control and, especially, traffic congestion and parking are included in the model. Where the CBD is crowded, fringe locations are preferred to renting in the $\mathrm{CBD}$ area.

Bollinger et al. [21] examined office rent models that control for building characteristics and lease terms using office data in the Atlanta region over three different periods: 4Q1990, 3Q1994 and 1Q1996. They found evidence to support the agglomeration economies of CBD and confirmed the earlier findings of Clapp [18]. In their models, the face-to-face convenience, which was represented by the concentration of professional workers and workers employed in fire and repair sectors, was found to be positively related to the office rent. Unlike the three studies reviewed earlier, which used building level data in the empirical analysis, Archer [19] attempted to study the intra urban location of offices, using firm level data collected from a questionnaire of office space usage conducted in Jacksonville, Florida and Hartford, Connecticut, during the summer of 1977. They found that linkages, which represent the need for face-to-face interaction among offices, were not significant as evidenced in Clapp [18] and Bollinger et al. [21] in affecting the firms' decisions to locate in downtown. He also showed that location of the market centrality is an important office location determinant only for the market-oriented firms, which find access to clients to be very important.

Some researchers believe that the advancement of information communication technology (ICT) will diminish the agglomeration economies of the CBD. The use of information communication technology in conveying information replaces the need for face-to-face interactions among firms in the city centre. The information communication technology enabled new working practises adopted by firms, like corporate downsizing, delayering, outsourcing, hot desking, to influence the tradeoff of space for accessibility of CBD office buildings, Gibson and Lizieri [27]; Sing [28].

However, Bollinger et al. [21] found no empirical evidence to support the hypothesis that face-to-face interaction can be substituted by the use of information communication technology. The debate surrounding the substitutability of the face-to-face importance in a CBD is, though, unresolved, but one likely phenomenon is that the agglomeration and information costs will go down with prevalent use of information communication technology. 
As a result of the lowering of information costs, coupled with increases in wage and commuting costs when a CBD grows in size, subcentres with competitive cost structure and agglomeration economies will be formed (Dipasquale and Wheaton [16]). The evidence of subcentres or submarkets was found by Dunse et al. $[29,30]$. They applied the empirical methodology developed by Bourassa et al. [31] to office markets in Glasgow and Edinburgh in the 1990s. The results showed that submarkets exist in Glasgow, with clearly distinguished spatial and property type characteristics, whereas the Edinburgh market is unitary.

Another limitation of the classical location theory is the implicit assumption that the agents who choose office space are homogeneous and rational with perfect information. The behavioural approach to analysis of office accommodation determinants has advocated the importance of studying the heterogeneity of firms and its decisions in the space selection. Leishman and Watkins [23] surveyed 119 office occupiers in the Edinburgh office market. They classified the office properties of the sample occupiers into four homogeneous clusters, based on the physical attributes of the properties, and then they showed that the choice of the office type by the firms is dependent on the characteristics of the firms, such as its size, type of business and its market coverage - either locally, regionally or nationally.

\section{Research design and methodology}

Primary and secondary data sources were used in order to resolve the research problem of this study. Structured interviews were conducted with estate agent firms in order to get rentals for a period from 2008 up to 2014 as part of primary data. The sample size was determined at $95 \%$ confidence level with a $5 \%$ margin of error and $40 \%$ chance that the picked respondents were dealing in offices. A sample size of 28 was obtained from the population of 30 estate agents in the telephone directory. The data that was obtained from the respondents was analysed using regression analysis models, Microsoft Excel and SPSS 16.0 package to determine the relationship between prosperity (GDP growth) and levels of rentals. The Moving average method (MAM) of office rentals between 2008 and 2014 was used to derive the direction of rental values in the four office nodes in Gaborone, namely Fairgrounds, New CBD, Main Mall and Finance Park. GDP growth was obtained using a desktop survey.

A field survey was undertaken to ascertain the nature of neighbourhoods and locations to determine the characteristics that can be used to project the forecasted office rentals. The responses were analysed and the average office rentals from the 30 respondents were computed using Microsoft Excel to come up with the mean and standard deviation of the mean. The results of this analysis are shown in table 1 and were used to project/forecast office rentals in the four locations in Gaborone using the moving average method (MAM). Model equations were developed in Microsoft Excel using the regression analysis to project/forecast rentals in the short and long term. The development pattern, nature of services and facilities, land use were taken into account when producing a trend on the forecasted office rentals for the City of Gaborone. The average rentals which were 
obtained from the respondents from 2008 up to 2014 were further analysed to establish if the independent variable (GDP growth) had an effect on the dependent variable (Office rentals) at $95 \%$ confidence level with a 5\% margin of error using SPSS. According to a study by Tsolacos [32] Gross Domestic product (GDP) was used as a broad indicator of economic activity that impacts on the occupier market and rental growth as far as property performance assessment is concrened. $\mathrm{He}$ further stressed that GDP growth also enters investors' assessment of the strength of the property market and economic risk to returns [32].

\section{Analysis and discussion of comparable rentals}

Table 1 illustrates the average rentals in the various locations obtainable from the market and their respective computed moving averages.

Table 1: Rentals in various locations and GDP growth.

\begin{tabular}{|c|c|c|c|c|c|c|c|c|c|c|}
\hline \multirow{2}{*}{ Year } & \multicolumn{8}{|c|}{ OFFICE RENT/Mㄹ (in Pula) } & \multirow[b]{2}{*}{$\begin{array}{l}\text { GDP } \\
\text { Growth }\end{array}$} & \multirow{2}{*}{ MA } \\
\hline & FG & MA & $\begin{array}{l}\text { New } \\
\text { CBD }\end{array}$ & MA & $\begin{array}{l}\text { Main } \\
\text { Mall }\end{array}$ & MA & FP & MA & & \\
\hline 2008 & 80 & & & & 88 & & 68 & & 2.9 & \\
\hline 2009 & 88 & 84 & & & 93 & 91 & 68 & 68 & -4.8 & -0.95 \\
\hline 2010 & 95 & 92 & 133 & & 105 & 99 & 83 & 76 & 7 & 1.1 \\
\hline 2011 & 103 & 99 & 128 & 131 & 105 & 105 & 88 & 86 & 5.7 & 6.35 \\
\hline 2012 & 95 & 99 & 123 & 126 & 98 & 102 & 95 & 92 & 4.12 & 4.91 \\
\hline 2013 & 93 & 94 & 113 & 118 & 80 & 89 & 88 & 92 & 3.9 & 4.01 \\
\hline 2014 & 75 & 84 & 110 & 112 & 73 & 77 & 70 & 79 & 4.95 & 4.43 \\
\hline
\end{tabular}

Source: Field survey.

Generally, the rentals from 2008 up to 2011 increased in all locations under investigation. An increase of $10 \%$ in rentals from 2008 to 2009 was noted except for Finance Park where it was stagnant. Between 2009 and 2010, rentals increased differentially in the locations with Finance Park showing an abnormally high increase of 22\% per annum, whereas Main Mall office rentals increased by $13 \%$ and Fairgrounds office rentals only increased by $8 \%$.

During the period of 2010 and 2011, Fairgrounds rentals maintained the increase per annum at $8 \%$; the new CBD suffered a decrease of $4 \%$ and Main Mall rentals experienced no increment in rentals $(0 \%)$ while Finance Park rentals experienced a lower increment of $6 \%$ per annum.

These uneven adjustments were as a result of more space that became available in the New CBD in 2011. This has affected the performance of commercial properties in these other locations due to its centrality, convenience and near Government Enclave. From 2012 up to 2014 rentals have continued to fall because of more space being availed in the New CBD which is now out numbering the effective demand of the commercial property sector. 
From figure 1 below it is evident that the rentals in the four locations reached a peak in 2011 and continually dropped up to 2014. The rentals are likely to continue dropping mainly due to the supply in the New CBD which will exceed the demand in the near future.

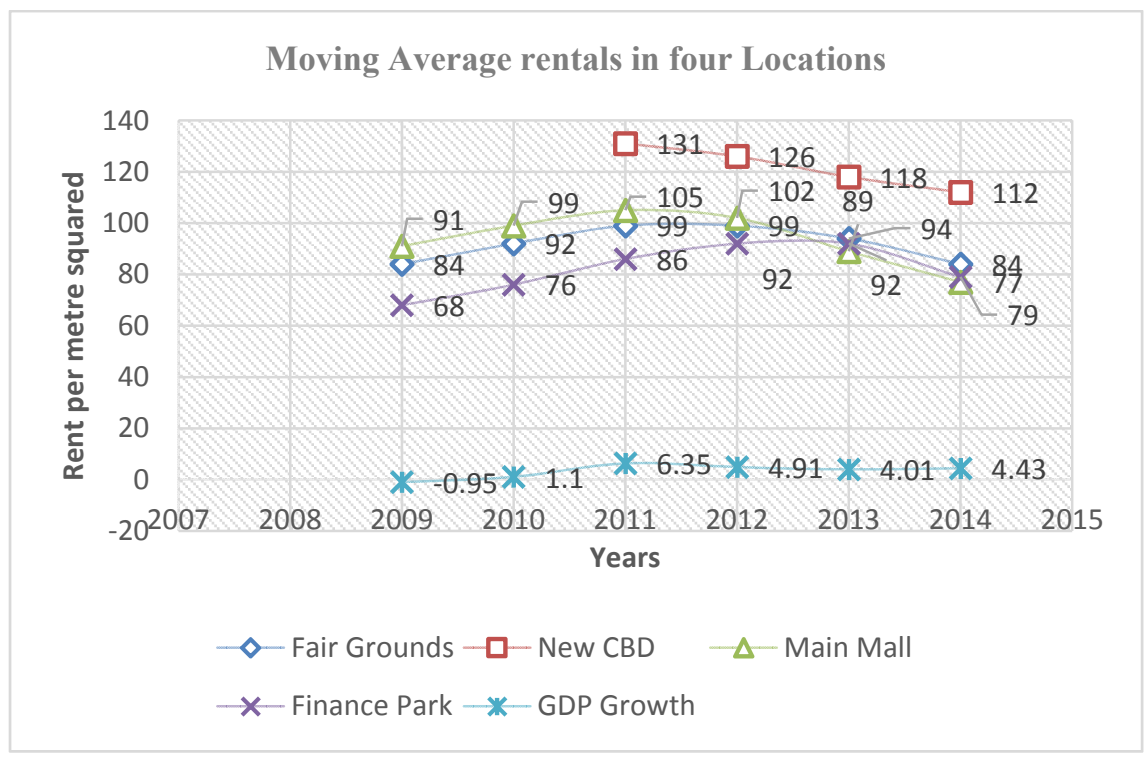

Figure 1: Trend of rentals (in Pula) in the four areas. Note: 1 Pula $=$ approx. US\$0.103. Rental rates are per month. (Source: Field survey.)

The forecasted rentals in Fairgrounds will rise to P92 per metre squared in the year 2015 and will continue to steadily go up in the next eight years when it will reach an average rental of P95 per metre squared in 2022. This trend will continue for the next twenty years from 2008 up to 2028 when the projected average rental will be P95.50 per metre squared.

Rentals were at the peak in the New CBD in 2010 at an average of P133 per metre squared and continued to drop up to P110 per metre squared in 2014. The projected rentals will drop to P111.70 per metre squared in the year 2015 and will continue to drop in the area for the next eight years when it will reach to an average rental of P73.00 per metre squared in 2022 as shown in figure 2. If no intervention is put in place, rental in this area will continue to drop until the twentieth year (2032) when it will have reached P8.00 per metre squared. These results do not look good for the New CBD. Already there are completed developments which are still vacant and if nothing is done about it, will spell doom for the area and the economy. The implication is that this market might collapse, unless Government takes protective steps. 


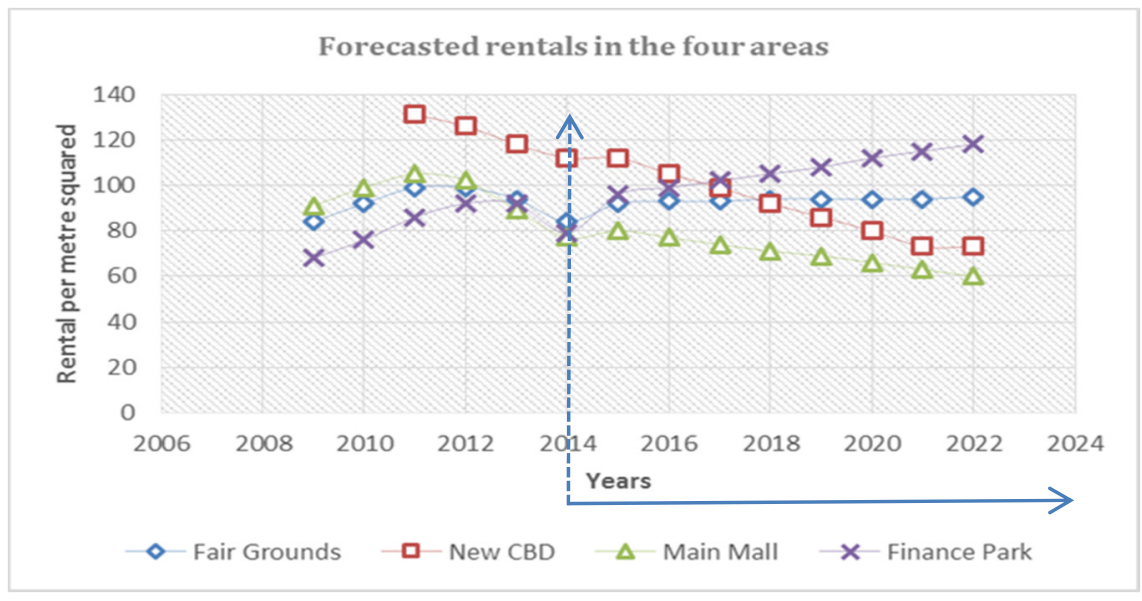

Figure 2: Forecasted rentals in the four areas. (Source: field survey.)

From the figure 2, forecasted office rentals in the Main Mall area will drop to P80 per metre squared in 2015 and will continue to steadily drop for the next eight years when it will reach an average rental of P60 per metre squared in 2022. This trend will continue for the next twenty years from 2008 up to 2028 with the projected average office rental of $\mathrm{P} 45$ per metre squared. The results show that the office rental will be almost half of what is being asked for now in twenty years to come.

In figure 2, it is evident that the office rentals for Finance Park reached a peak in 2012 at P95 per metre squared and dropped to P70 per metre squared in 2014. Rentals will increase to P96 per metre squared in 2015 and continue to steadily rise in the area for the next eight years when it will reach to an average rental of P118 per metre squared in 2022. This trend will continue for the next twenty years from 2008 up to 2028 with the projected average rental of P133 per metre squared. The results show that the rental will be almost double of what is being asked for now in twenty years to come.

From the figures 1 and 2, a model for forecasting rentals in the four areas can be developed as highlighted below:

a. Model for forecasting rental in Fairgrounds Area

$$
\mathrm{Y}=0.2143 \mathrm{X}+91.167
$$

b. Model for forecasting rental in New CBD Area

$$
Y=-6.45 X+137.50
$$

c. Model for forecasting rental in Main Mall Area

$$
\mathrm{Y}=-2.9571 \mathrm{X}+103.93
$$

d. Model for forecasting rental in Finance Park Area

$$
\mathrm{Y}=3.1143 \mathrm{X}+70.933
$$


The hypothesis was evaluated in order to establish whether there is a relationship between the level of office rentals and GDP growth which is the economic performance of a country. From the graphical outlook in figure 1 it is clear that rentals are related to the economic performance of the country. Both rentals and GDP growth are declining. The Null hypothesis was that there is no relationship between rentals and GDP growth. To establish this, a t-test was used at $95 \%$ confidence level with a critical value of 1.96 . The computed t-value of 2.015 from SPSS is higher than the critical value 1.96. This means that we reject the Null hypothesis and accept the Alternative hypothesis which states that there is a statistically significant relationship between rentals and GDP growth.

Table 2: Coefficients of the relationship between office rentals and GDP growth (general economy).

\begin{tabular}{|c|c|c|c|c|c|}
\hline \multirow{2}{*}{ Model } & \multicolumn{2}{|c|}{ Unstandardized coefficients } & Standardized coefficients & & \\
\cline { 2 - 5 } & $\mathrm{B}$ & Std. Error & Beta & $\mathrm{t}$ & Sig. \\
\hline (Constant) & 85.996 & 3.629 & & 23.698 & 0.000 \\
\hline GDP Growth & 1.803 & 0.895 & 0.710 & 2.015 & 0.114 \\
\hline
\end{tabular}

The expected rental in 2015 if the GDP growth is 4\% for Fairgrounds will be $y=86+1.8 * 4=$ P93 per square metres with a standard error of 3.629 on the constant as well as 0.895 on the GDP growth. It is evident that there is a statistically significant relationship between rentals and the GDP growth at the $95 \%$ confidence level. The correlation coefficient of 0.710 still indicate a relatively strongly relationship between the two variables being office rental and GDP growth.

\section{Conclusion and recommendations}

From the analysis, it is clear that the forecasted and projected rentals in Fairgrounds and Finance Park will continue to rise and perform better than other areas, (New CBD and Main Mall). The former two areas are in the outskirts of Gaborone City. The implication is that because of accessibility and convenience in travel time during peak periods, rentals in the areas in the inner city will continue to decline unless Government intervenes to rectify this situation. The forecasted rentals using the moving average rentals in the four areas were plotted graphically to give a pictorial impression of what will happen. The model equations were developed using linear regression analysis in the times series for the period 2009 up to 2014 and were used for predicting rentals in the short and long term.

It is clear that these two areas will continue to struggle in terms of rental performance due to low demand as exerted by the high absorption rate in the New 
CBD by corporate firms, resulting from its proximity to markets and decision makers in government offices.

The property market as a whole, however, is expected to perform well due to prevailing economic conditions in Botswana and Gaborone. It is recommended that Investors should take note of the results and perhaps use them to make informed decisions when investing in these areas.

\section{References}

[1] IPD, "Botswana property market," www.ipd.com. Accessed 23 July 2013, 2012.

[2] Botswana Review, Botswana review of Commerce and Industry, 33 ed., Gaborone: B \& T Directories (Pty) Ltd, 2014.

[3] C. E. Cloete, Ed., Management of Commercial and Industrial properties, Sandton: South African Property Education Trust, 2002.

[4] M. Serero and J. Kampamba, "An analysis of the housing market in Botswana," Unpublished, BLM 200 Dissertation, Department of Civil Engineering, University of Botswana, Gaborone, 2013.

[5] J. Kampamba and C. E. Cloete, "The problems and prospects of the office market in Botswana," Unpublished, MSc Dissertation, Department of Construction Economics, University of Pretoria, Pretoria, 2006.

[6] O. T. Oni, O. M. Bello and O. A. Oni, "Forecasting demand for office spaces in Ikeja, Nigeria," Mediterranean Journal of Social Sciences, 3(1), pp. 323-338, 2012.

[7] C. C. Nwuba, "An analysis of office rent movement in Abuja.," Nigerian Journal of Education, 7(1), pp. 1-11, 2008.

[8] O. A. Oni, "Arterial Road Network and Commercial Property Values in Ikeja, Nigeria," Unpublished, 2009.

[9] G. Matysiak and S. Tsolacos, "Identifying short-term leading indicators for real estate rental performance," Property Investment \& Finance, 21(3), pp. 212-232, 2003.

[10] S. Kiehela and H. Falkenbach, "Modeling and forecasting central Helsinki office rents," International Journal of Strategic Property Management, 18(3), pp. 292-306, 2014.

[11] T. McGough and S. Tsolacos, "Forecasting commercial rent values using ARIMA models," Property Valuation and Investment, 13(5), pp. 6-22, 1995.

[12] A. Marshall, Principles of Economics, New York: The Macmillan Company, 1961.

[13] P. Krugman, Geography and Trade, Cambridge MA: MIT Press, 1991.

[14] J. E. Rauch, "Does history matter only when it matters little? The case of city industries location," The Quarterly Journal of Economics, 108(3), pp. 843-867, 1993.

[15] H. W. Richardson, Urban Economics, Hinsdale, Illinois: The Dryden Press, 1978. 
[16] D. Dipasquale and W. C. Wheaton, Urban Economics and Real Estate Markets, Englewood Cliffs: Prentice Hall, 1996.

[17] M. Ball, C. Lizieri and B. MacGregor, The Economics of commercial property markets, London: Routledge, 1998.

[18] J. Clapp, "The intermetropolitan location of office activities," Journal of Regional Science, 20(3), pp. 389-399, 1980.

[19] W. R. Archer, "Determinants of location for general purposes office firms within medium size cities," AREUEA Journal, 9, pp. 283-297, 1981.

[20] J. H. Dunning and G. Norman, "The location choices of offices of international companies," Environmental and Planning, 19, pp. 613-631, 1987.

[21] R. C. Bollinger, K. R. Ihlandfeldt and R. D. Bowes, "The spatial variation in office rents within the Atlanta region," Urban Studies, 35(7), pp. 1097$1118,1998$.

[22] P. Wyatt, Can a geography analysis of a property values aid business location Planning?, Cambridge: University of Cambridge, 1999.

[23] C. A. Leishman and C. Watkins, "The decision making behaviour of ofice occupiers," Journal of Property Investment and Finance, 22(4), pp. 307$319,2004$.

[24] C. A. Leishman, N. A. Dunse, F. J. Warren and C. Watkins, "Office space requirements: comparing occupier's preferences with agents' perceptions," Journal of Property Investment and Finance, 21(1), pp. 45-60, 2003.

[25] W. Alonso, Location and Land use, Cambridge: Harvard University Press, 1964.

[26] R. Sivitanidou, "Urban Spatial variations in office - commercial rents: The role of spatial amenities and commercial zoning," Journal of Urban Economics, 38, pp. 23-49, 1995.

[27] V. A. Gibson and C. M. Lizieri, "Friction and inertia: business change, corporate real estate portfolios and the U.K. office market," Journal of Real Estate Research, 22(1/2), pp. 59-79, 2001.

[28] T. F. Sing, "Impact of Information and Communication Technology on office space demand," in Paper presented at the 9th European Real Estate Society (ERES) conference, Glasgow, Scotland, 2002.

[29] N. A. Dunse, C. A. Leishman and C. Watkins, "Classifying office submarkets:," Journal of Property Investment and Finance, 19(3), pp. 236250, 2001.

[30] N. A. Dunse, C. A. Leishman and C. Watkins, "Testing for the existence of office sub markets; a comparison evidence from two cities," Urban studies, 39(3), pp. 483-506, 2002.

[31] W. B. Bourassa, F. Hamelink, M. Hoesli and B. MacGregor, "Defining housing submarkets," Journal of Housing Economics, 8, pp. 160-183, 1999.

[32] S. Tsolacos, "An assessment of property performance forecasts: consensus versus econometric," Journal of Property Investment and Finance, 24(5), pp. 386-399, 2006. 